\title{
The Impact of Personalized Information on Vote Intention: Evidence from a Randomized Field Experiment
}

\author{
Joëlle Pianzola, ETH Zurich \\ Alexander H. Trechsel, University of Lucerne \\ Kristjan Vassil, University of Tartu \\ Guido Schwerdt, University of Konstanz \\ R. Michael Alvarez, California Institute of Technology
}

\begin{abstract}
Voting advice applications (VAAs) are voter information tools that millions of individuals have used in recent elections throughout the world. However, little is known about how they affect political behavior. Until now, observational studies of VAA have produced inconclusive results. Here we present the results from a randomized field experiment in Switzerland that estimates the causal effects of VAA use on voters' vote intentions. Our results suggest that usage of the Swiss VAA smartvote strengthened the vote intention for the most preferred party and also increased the number of parties considered as potential vote options. These results imply that VAAs can influence voting behavior and that they can play an important role in electoral politics.
\end{abstract}

$\mathrm{n}$ this article, we use a randomized field experiment to determine whether voters are affected by information provided by smartvote (http://www.smartvote.ch), a popular voting advice application (VAA) used in the 2011 Swiss national elections. ${ }^{1}$ VAAs are online tools that provide voters with tailor-made voting recommendations based on algorithms that match a voter's responses to issue questions with political parties (Trechsel and Mair 2011). VAAs have proliferated, are quite popular in Western European multiparty systems, have become a standard part of the elections in many nations, and have been used to study political behavior in different contexts (e.g., Dinas, Trechsel, and Vassil 2014; Enyedi 2015; Garzia and Marschall 2012, 2014; Gemenis and
Rosema 2014; Lefevere and Walgrave 2014; Maheo 2016; Otjes and Louwerse 2014; Pajala et al. 2017; Wheatley 2016). As they provide voters with extensive information, VAAs may have a variety of effects on voter preferences and behavior. They might help voters form, change, or reinforce their political preferences, as well as alter their stated vote intentions and influence the party they vote for.

To ascertain the causal influence of smartvote use on vote intention, we carried out an online field experiment during the 2011 Swiss federal elections. The Swiss case is of particular interest for VAA research for three reasons: first, the Swiss electoral system is very open, allowing voters to select candidates of different parties on their ballot. Second, it has

Joëlle Pianzola (joelle.pianzola@gess.ethz.ch) is the executive director of the Immigration Policy Lab at ETH Zurich, Department of Humanities, Social and Political Sciences, Leonhardshalde 21, LEH D 3, CH-8092, Switzerland. Alexander H. Trechsel (alexander.trechsel@unilu.ch) is full professor of political science and political communication at University of Lucerne, Frohburgstrasse 3, PO Box 4466, 6002 Lucerne, Switzerland. Kristjan Vassil (kristjan.vassil@ut.ee) is senior researcher at the Johan Skytte Institute of Political Studies, University of Tartu, Lossi 36, 51003, Tartu, Estonia. Guido Schwerdt (guido.schwerdt@uni-konstanz.de) is professor of public economics at the University of Konstanz, Department of Economics, Box D133, 78457 Konstanz, Germany. R. Michael Alvarez (rma@hss.caltech.edu) is professor of political science at the California Institute of Technology, Division of the Humanities and Social Sciences, Mail Code 228-77, Pasadena, CA 91125.

Data and supporting materials necessary to reproduce the numerical results in the article are available in the JOP Dataverse (https://dataverse .harvard.edu/dataverse/jop). An online appendix with supplementary material is available at https://dx.doi.org/10.1086/702946.

1. Smartvote produces voting recommendations to users on the basis of their policy congruence with parties and candidates running for office. The premise of the tool follows the logic of proximity voting (Downs 1957) and calculates the overlap of a 75-item survey on policy positions that both users and candidates fill out individually. For the 2011 Swiss federal elections, 84\% of all running candidates for the National Council (the Swiss Parliament's Lower Chamber) participated on the smartvote website. Among the newly elected members of Parliament, $93 \%$ had a candidate profile on smartvote (data obtained from the smartvote website on statistics, available at http://smartvote.ch/11_ch_sr/statistics/candidate?lang=en_GB).

The Journal of Politics, volume 81, number 3. Published online April 23, 2019. http://dx.doi.org/10.1086/702946

(c) 2019 by the Southern Political Science Association. All rights reserved. 0022-3816/2019/8103-0005\$10.00 
a large number of effective parties and one of the most complex party systems in the world. Finally, VAAs are widely used by citizens during election campaigns. We employed an encouragement design, randomly assigning voters to receive an invitation letter to use smartvote before the national elections. This was accompanied by a pre- and postelection survey among participants, rendering a study design that allows us to deduce causal effects from smartvote use on vote intentions.

\section{THEORY}

For voters, the formation of vote intentions is an important component of their electoral decision-making process. Voters form their vote intentions for parties and candidates, which then provide the baseline for making a choice in an election. We focus on these baseline vote intentions for political parties, formed and updated during the course of a campaign, eventually leading to a choice at the polls. Distinguishing the process of generating vote intentions from the actual vote choice is essential since looking only at the final decision might conceal important changes in the previous intentions of the voter (Alvarez 1998). Thus, if we want to examine the extent to which a certain type of information during an electoral campaign (more specifically, information generated by a VAA) is influential to voters, we need to look at changes in vote intentions and the precision of these intentions and not just at the choices voters make on election day.

What does it take for political opinion and behavior to change? Empirical evidence suggests that political preferences and attitudes are uncertain (Alvarez 1998; Alvarez and Franklin 1994; Bartels 1986, 1996; Franklin 1991) and amenable to new information (Alvarez 1998; Barker and Hansen 2005; Lau and Redlawsk 2006). Most people hold policy preferences that reflect inconsistent belief systems, since they can be overwhelmed and misled by the various policy proposals and debates that litter the political landscape (Alvarez and Brehm 2002; Kuklinski and Peyton 2007, 45). The public's knowledge of politics and policy positions repeatedly turns out to be ill-informed, ambivalent, and even arbitrary (Althaus 2003, 12; Bartels 1996; Converse 1964; Luskin 2002). Not surprisingly, studies show that many citizens have great difficulty placing political parties on the left-right axis on the basis of their policy programs (MacKuen et al. 2003, 205). In the context of multiparty electoral systems, Walgrave et al. (2009) have found that voter's perceptions of party positions differ substantially from the actual party positions, with the information gap leading voters to opt for parties that do not necessarily reflect their values and interests. Experimental work has furthermore indicated that citizens tend to reconsider initial choices after new information on specific candidates becomes available (Barker and Hansen
2005; Lau and Redlawsk 2006). Generally, vote intentions that are expressed by voters seem to diverge from hypothetically fully informed vote intentions, ascribing a vital role to the information voters possess (Bartels 1996; Fournier 2009, 49; Lau and Redlawsk 1997, 2006).

VAAs give their users an opportunity to match their political preferences with the policy positions of parties and candidates running in the elections (e.g., Cedroni and Garzia 2010). These tools offer a large amount of party/candidatespecific information, and the direct comparison of the voter's political opinions with the positions taken by parties or candidates can lower the information gathering and processing costs for voters. VAAs give voters information on the positions of the parties in the multidimensional issue space and provide voting advice, usually presented in the form of a list of candidates or parties running in the elections, ranked according to the overlap in preferences between them and the users (Alvarez et al. 2014; Dinas et al. 2014).

The information provided by the VAA can have a variety of effects on a voter. First, it can change vote intentions for particular parties without affecting the rank order of parties. Second, it can alter vote intentions while also changing the rank order of parties. In both cases, change occurs: once only in terms of magnitude and once both in terms of magnitude and ordering. Finally, it may have no affect at all on the voter's vote intentions, especially for voters with strong partisan ties, who might not be as susceptible to new information and who might be skeptical of information provided by a VAA.

In order to understand potential changes in vote intentions during an electoral campaign, we adopt a Bayesian perspective of voter learning. Bayesian learning theory stipulates that a voter has prior perceptions that can be updated by new information, resulting in revised posterior beliefs (Achen 1992; Alvarez 1998, 42; Bartels 2002; Fiorina 1977, 1981; Lenz 2009). As such, voters' current beliefs are susceptible to modification in light of new events, with the degree of susceptibility a function of how precise their beliefs are. The logic behind updating represents priors, information, and posterior beliefs as distributions with means and variances. The variance of the distribution indicates the precision with which beliefs are held. In updating prior beliefs with new information, their distributions are combined, resulting in a new distribution of posterior beliefs. Hence, both the degree of prior knowledge and the nature of the information matter in Bayesian updating. Translated into the electoral context, a voter has some belief about the positions of the parties running in the elections. With new information on particular parties and candidates provided by the VAA, a voter might be inclined to revise his or her previously held convictions and adapt his or her vote intention 
accordingly. The extent of change depends on the precision of both the prior knowledge and the new information. Since we expect users to generally possess uncertain priors, they should be sensitive to the detailed and precise information provided by the VAA. Using the Bayesian perspective, we thus expect that VAA users will be more likely to update their prior beliefs, which should in turn produce changes in their vote intentions.

We argue that there are two main mechanisms at work through which new information may lead to change in vote intentions. According to the first mechanism, new information stemming from the VAA experience passes a user's "perceptual screen" of partisan affiliation (Campbell et al. 1960). The new information is interpreted by the user in a way to limit her cognitive dissonance (Bartels 2002; Dinas 2014; Festinger 1957; Gaines et al. 2007). This in turn can lead to the reinforcement of prior vote intentions through a process of motivated reasoning (Kunda 1990; Lodge and Taber 2000, 2013; Taber and Lodge 2006). Users thus follow a directional goal of protecting their prior partisan beliefs, rationalizing the new information accordingly and, with it, strengthen their priors. The second mechanism leads to more ambivalent vote intentions. Through the exposure to new information on a variety of parties, "conflicting partisan evaluations" (Lavine, Johnston, and Steenbergen 2012) may be generated, triggering ambivalence in vote intentions. In other words, users are confronted with alternatives to their prior vote intentions, representing enhanced and diversified choice sets, which in turn lead to ambivalence. Partisans who are initially committed to their vote intentions may therefore become, through exposure to conflicting partisan evaluations, ambivalent.

The Swiss setting is an ideal one for studying the potential effects of VAA use on vote intentions. First, it has a rather fragmented party system with a large number of parties. With each additional party running in an election, the overall information on party positions becomes more complex for the voter to obtain and assess. VAAs should thus be particularly useful to voters in complex election contexts. Second, it is among the most open systems in the world (Kriesi and Trechsel 2008). Switzerland has an open ballot proportional representation (PR) electoral system in which voters not only choose a party but can also cast preference votes for candidates within and across parties (Lutz 2010). Voters thus typically have more than one vote to cast and can select from candidates of different parties on their ballot. In the context of a multiparty system in which multiparty ballots are possible, voters might be both less certain about the positions of parties and candidates and less fixed in their party rankings relative to voters in electoral systems with a single party choice. Moreover, because of Switzerland's federal structure, a multitude of subnational (cantonal) party systems prevail (Ladner 2004). Hence, electoral behavior might be more susceptible to campaign information in an open ballot multiparty electoral context in general and even more so under the Swiss system in particular. Finally, Switzerland is one of the early adopters of VAAs. Although first proposed in the Netherlands, VAAs have taken a prominent role during electoral campaigns in Switzerland, at both federal and cantonal levels.

Since 2003, the Swiss VAA smartvote allows candidates to position themselves by filling out an online questionnaire a few weeks before an election. The questionnaire is developed by the nonprofit, nongovernmental organization Politools, based in Bern, the capital of Switzerland. The experts at Politools are mostly political scientists, who develop the questionnaire to cover the topics likely to come up during the electoral campaign. There are two versions of the questionnaire, a long form (containing 75 questions) and a short form, made up of 30 questions. Candidates can answer each question on a four-point scale ranging from "yes" to "rather yes," "rather no," and "no." One can also actively chose not to answer the question (i.e., not to take a stance on an issue). Any interested person can subsequently fill out the same questionnaire and a simple algorithm (Euclidian distance) matches the person's answers with those given by all the candidates who participated in the smartvote tool. In the most recent federal elections of October 2015, approximately 3,300 candidates answered the questionnaire proposed by smartvote, corresponding to some $85 \%$ of all candidates running in the elections. Furthermore, smartvote produced over 1.3 million voting recommendations, corresponding to roughly one-quarter of Switzerland's voting age population. ${ }^{2}$ Smartvote is highly trusted by its users (Ladner and Pianzola 2010), and the growing number of users shows smartvote's popularity with Swiss voters (Pianzola 2014a, 11). For these reasons, the Swiss case presents an ideal laboratory for the assessment of potential VAA-induced effects on vote intentions.

Given the abundance of political alternatives and the complex ballot structure imposed by the Swiss electoral system, we expect voters to have certain anchoring points for their vote intentions. Psychological attributes associated with cognitive consistency (Lau and Redlawsk 2006) make it more likely that voters will change the intensity of their intentions with new information rather than completely revise their beliefs during a campaign. Thus, it is more likely that recommendations of a VAA will strengthen the prior beliefs of voters, rather than completely revise them. Following the Bayesian updating of

2. Smartvote dominates the VAA landscape in Switzerland: its direct competitor Vimentis generated around 200,000 voting recommendations before the 2015 federal elections. 

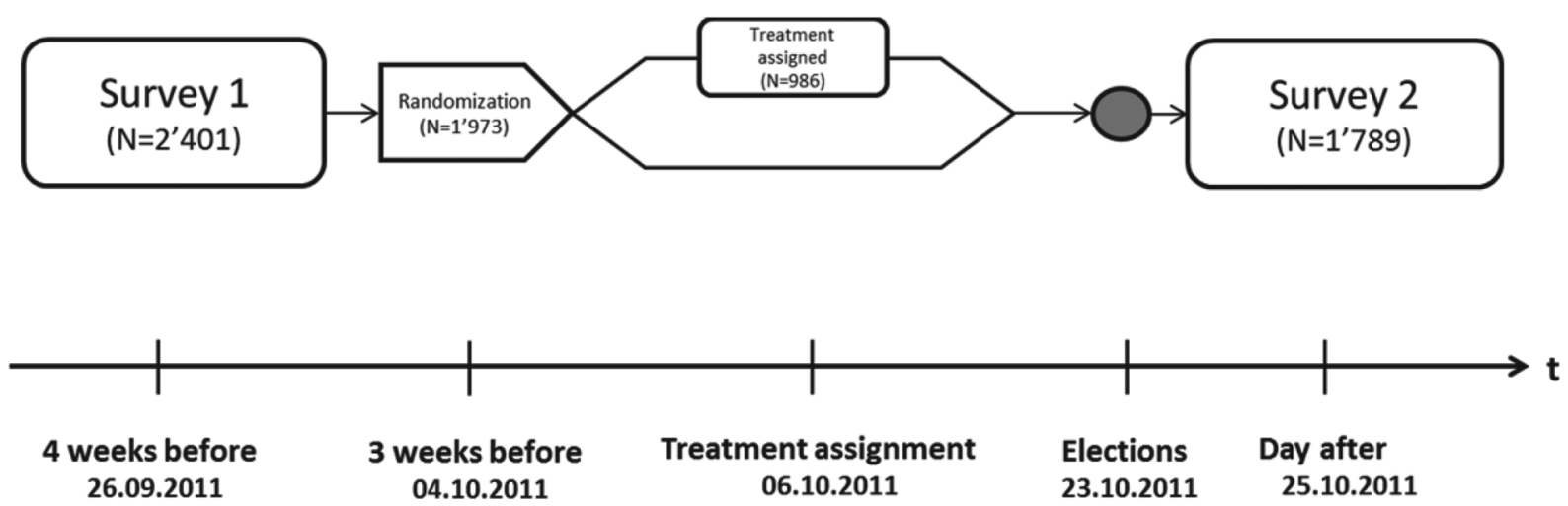

Figure 1. Experimental setup

posteriors in light of new information, we expect that in addition to the strengthening of one's vote intention for a party, vote intentions for alternative parties may also be strengthened. Consequently, less preferred alternatives might therefore gain attention because voters learn that they reflect their political desires unexpectedly well. This is particularly likely in an extremely open electoral system like that of Switzerland.

Following our theoretical argument and the context in which the smartvote application operates, we propose two hypotheses to test these potential effects:

H1. The information gained through smartvote use is expected to strengthen a user's vote intention for his or her most preferred party.

H2. The information gained through smartvote use is expected to lead users to evaluate more than one party favorably since the comparative nature of the recommendation will reveal politically attractive partisan alternatives.

\section{THE FIELD EXPERIMENT}

As has been noted frequently in the "campaign effects" literature, methodological issues and measurement problems have stood in the way of reliable and accurate estimates of how much voters learn from campaigns (e.g., Bartels 1993). In order to obviate many of the potential measurement and methodological problems seen in previous observational studies on VAAs (Pianzola 2014b), we conducted a field experiment during the 2011 Swiss federal elections to assess the causal effect of VAA use on voter learning in the context of this electoral campaign.

Our experimental setup is shown in figure 1. At the end of September 2011, four weeks before the parliamentary elections in Switzerland, an e-mail was sent to students of four univer- sities in the German-speaking part of Switzerland, asking them to participate in a research project on elections (survey 1). We pointed to the upcoming elections and explained that the nature of the survey is to study political behavior in a broad sense; however, the goal of the experiment was not revealed to participants. We explicitly stated that there would also be a second survey after the elections. An online link in the e-mail brought students directly to our online survey. ${ }^{3}$

The e-mail with the link to the preelection survey went to 8,715 students of the University of Zurich and ETH Zurich, 12,024 students of the University of Bern, and 2,691 students of the University of Lucerne. Out of these 23,430 students, $2,401(10 \%)$ completed the preelection survey. At the end of the preelection survey, we asked students to provide us with an e-mail address to allow us to contact them again for our postelection survey. ${ }^{4}$ Among the 2,401 students who completed the first survey, 1,973 provided us with their e-mail address for the postelection wave (survey 2 in fig. 1).

\section{Randomization and treatment assignment}

The sample of 1,973 students was then randomly split into two groups. The treatment group $(N=986)$ received an e-mail that invited them to use smartvote before the 2011 Swiss federal elections. ${ }^{5}$ We explained that this additional request was part of our research but did not mention that only a randomly selected group received this e-mail. We then incentivized the use of smartvote by a lottery (students complying with

3. A transcript of the contact e-mail and the complete survey questionnaire is available from the authors.

4. This procedure was necessary, as the participating universities were not able to provide us with e-mail addresses of students directly for legal reasons. The e-mail with the link to the preelection survey was sent by the universities themselves via their e-mail distribution lists.

5. We use the terms treatment and control groups to refer to the experimental groups of e-mail recipients and non-e-mail recipients. Figure A.1 (figs. A.1 and A.2 are available online) provides the English translation of the e-mail treatment. 
our request to use smartvote could win an iPad 2). We supplied the treatment group participants with a personalized login for the website. The control group $(N=987)$ was not contacted between the pre- and postelection survey.

The postelection survey (survey 2) was sent to both groups the day after the elections. Participants were asked to indicate their vote choice and other relevant aspects of their voting behavior and political preferences. Most importantly with regard to treatment assignment, we asked all participants whether they had used smartvote for the 2011 election. Out of the initial sample of 1,973 participants, 1,789 (91\%) answered the postelection survey. ${ }^{6}$ Table 1 reports selected average background characteristics of participants by treatment status. The table shows that our procedure yielded a well-balanced sample between the treatment and control group, with no significant differences between the two.

\section{Measuring change in vote intentions}

The main outcome of interest in this study is change in vote intention. We operationalize change in vote intention based on the propensity to vote (PTV) measure (van der Eijk and Niemoeller1984), which seeks to measure the utility voters ascribe to parties in a multiparty context. The PTV measure captures the voting inclination for specified parties running in the election. Voters are asked to indicate how likely it is that they will ever vote for a specific party. This question is asked for every party included in the research design. The scale ranges from 0 to 10 , with 0 indicating that the respondent estimates that it is very unlikely that she will ever vote for that particular party, and 10 indicates that she is very likely to vote for that particular party at some point in time.

We let participants rate the eight major parties in Switzerland on the PTV scale in the first survey wave (pretreatment) as well as in the second survey wave (posttreatment). Given the panel design of our experimental setup, systematic changes in PTV scores can subsequently be ascribed to smartvote use. The following example (depicted in fig. 2) illustrates the PTV measure and its use for operationalizing change in vote intention. Before the elections and before the treatment $(t-1)$, the participant indicates on the PTV scale how likely it is that she will ever vote for the listed parties. Party A receives a PTV score of 9, party B a PTV score of 7, and party C a PTV score of 5. After the elections and posttreatment $(t)$, the participant rates the same parties once more on the PTV scale. This time

6. The attrition rate of $9 \%$ in the second survey was not systematicthere was no effect of treatment assignment on the probability for participation in the second survey wave $(-.004, p>.1)$.

7. In terms of party predispositions, treatment and control group were well balanced, with similar average PTV scores for the specific parties (see table A.1, available online). party A receives a PTV score of 10, party B a PTV score of 9, and party $\mathrm{C}$ a PTV score of 5 . This example shows two changes in party vote intentions: first, the respondent's intention for her highest ranking party in $t-1$ was strengthened in $t$. Second, this respondent's second highest rated party intention was also strengthened posttreatment. These are exactly the kind of changes in party vote intentions that we are interested in.

To measure change in the PTV for the most preferred party (corresponding to our first hypothesis), we calculate the difference in the top PTV score between $t$ and $t-1$ (Difference in top PTV score), where positive values correspond to an increase in the top party preference posttreatment. To assess whether the most preferred party before the election still receives the highest PTV score after the election, we coded a binary measure that indicates whether participants changed their top PTV party (1) or whether they stayed with their initial party preference $(0)$. We label this outcome variable of interest Same top PTV party.

To operationalize general shifts in partisan vote intentions, we draw from the literature on PTV measures (van der Eijk and Franklin 2009; van der Eijk and Oppenhuis 1991; van der Eijk et al. 2006) and classify voters in terms of their availability for electoral competition. We borrow this concept from Peter Mair's notion of the "available electorate," referring to those voters who can imagine voting for more than one party (Mair 1987; see also Bartolini 2002, 93; Bartolini and Mair 1990). Such voters are considered to be ambivalent partisans (Lavine et al. 2012). To operationalize ambivalence, we proceed as follows: if a user has more than one strong party intention (i.e., he or she rates more than one party above 7 points on the 0 10-point PTV scale), we declare her a user with multiple (strong) party vote intentions. Hence, a variable for multiple high party intentions takes the value of 1 for voters who award more than one party a high PTV score (8-10) and 0 for the others. Given this binary measure, we can classify participants in terms of their "availability" for electoral competition both pre- and posttreatment. This allows us to test our second hypothesis. Using this binary coding, the following four scenarios are possible (see table 2).

In scenarios 1 and 2, a user's availability for electoral competition stays the same. In scenario 3, a user changed her vote propensities so that posttreatment she now gives more than one party high PTV scores, so she is now newly "available" to electoral competition by holding multiple (strong) party vote intentions. The reverse situation occurs in scenario 4. A user who initially considered multiple parties as valid vote options now shifted her intentions in a way that her "availability" for electoral competition falls. In a first step, we test whether shifts in terms of availability for electoral competition are more likely 
Table 1. Descriptive Statistics by E-Mail Treatment Status

\begin{tabular}{|c|c|c|c|c|}
\hline \multirow[b]{2}{*}{ Variable } & \multirow[b]{2}{*}{ Control Group } & \multirow[b]{2}{*}{ Treatment Group } & \multicolumn{2}{|c|}{ Treatment-Control } \\
\hline & & & Difference & $p$ \\
\hline E-mail received & .00 & 1.00 & 1.00 & \\
\hline Smartvote used & .69 & .83 & .14 & .00 \\
\hline \multicolumn{5}{|l|}{ Demographic characteristic: } \\
\hline Female & .50 & .50 & -.01 & .76 \\
\hline Age & 25.18 & 25.07 & -.11 & .72 \\
\hline \multicolumn{5}{|l|}{ Level of education: } \\
\hline High school & .53 & .53 & -.00 & .98 \\
\hline Bachelor (nonacademic) & .03 & .02 & -.01 & .05 \\
\hline Master (nonacademic) & .00 & .00 & -.00 & .71 \\
\hline Bachelor (academic) & .26 & .26 & -.00 & .99 \\
\hline Master (academic) & .16 & .16 & .00 & .92 \\
\hline $\mathrm{PhD}$ & .01 & .02 & .01 & .08 \\
\hline \multicolumn{5}{|l|}{ University: } \\
\hline Bern & .57 & .52 & -.04 & .07 \\
\hline Lucerne & .16 & .18 & .03 & .15 \\
\hline Zurich & .27 & .28 & .01 & .68 \\
\hline \multicolumn{5}{|l|}{ Field of study: } \\
\hline Social sciences & .48 & .47 & -.02 & .43 \\
\hline Medicine & .08 & .10 & .02 & .13 \\
\hline Natural sciences & .16 & .14 & -.02 & .27 \\
\hline Law & .16 & .18 & .01 & .47 \\
\hline Economics & .10 & .10 & -.01 & .71 \\
\hline \multicolumn{5}{|l|}{ Interest in politics: } \\
\hline Not interested at all & .00 & .00 & .00 & 1.00 \\
\hline Rather not interested & .07 & .06 & -.01 & .33 \\
\hline Rather interested & .42 & .46 & .04 & .11 \\
\hline Very interested & .50 & .48 & -.03 & .26 \\
\hline Observations & 889 & 886 & & \\
\hline
\end{tabular}

Note. Group means by treatment status. Treatment refers to randomly assigned e-mail receipt before the election. The last two columns present differences in means between the treatment and control group together with $p$-values. All variables are measured in the first survey wave before the election. Survey data were specifically collected in connection with the smartvote experiment conducted in 2011.

to occur among smartvote users than among nonusers. ${ }^{8}$ We label this binary outcome variable of interest Change in multiple intentions. In a second step, we are particularly interested in those users who initially did not have several parties they considered as viable options but changed their party vote intentions in a way that they are now open to electoral competition (scenario 3). The binary variable Newly available to electoral competition measures whether a switch toward multiple party vote intentions occurred and takes the value of 1 for

8. On the basis of the average distribution of PTV scores in the national Swiss Electoral Studies (Selects), $72 \%$ of all voters in Switzerland have a single top PTV party and thus do not hold multiple (strong) party vote intentions. those respondents who changed their status on multiple preferences from 0 to 1 between the elections (scenario 3 ) and 0 otherwise.

\section{Empirical strategy}

The estimation of the effect of receiving the e-mail on various outcomes is straightforward. Given the random assignment of the e-mail treatment in our field experiment, we can obtain an unbiased estimate of the causal effect of receiving information about smartvote on vote intentions by regressing changes in the outcomes of interest on a dummy indicating e-mail receipt:

$$
y_{i}=\phi \mathrm{e}-\mathrm{mail}_{i}+\lambda_{0}^{\prime} Z_{i}+\varepsilon_{i}
$$




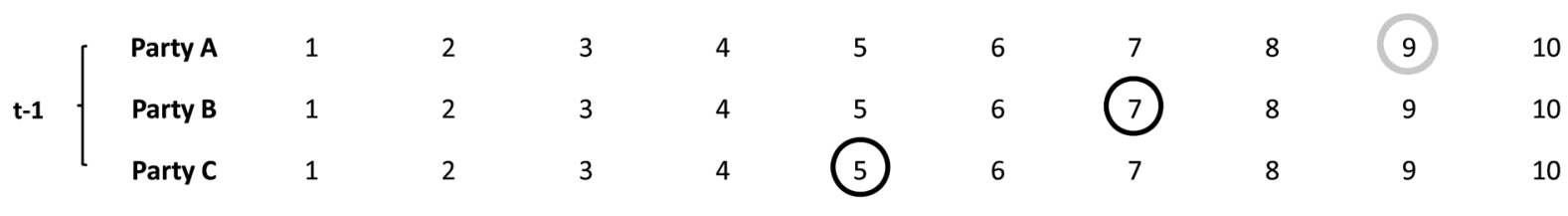

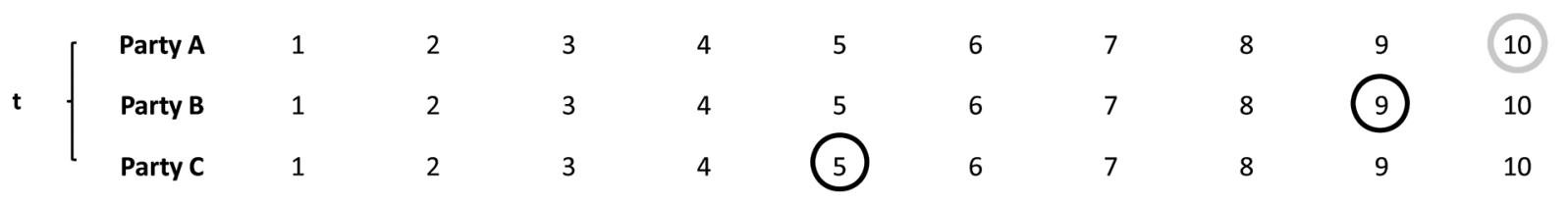

Figure 2. Measuring change in partisan vote intentions on the propensity to vote scale

where $y_{i}$ is the outcome of interest for individual $i$, e-mail $l_{i}$ is an indicator of whether individual $i$ received the e-mail, $Z_{i}$ is a vector of control variables, and $\varepsilon_{i}$ is an error term uncorrelated with all right-hand-side variables. ${ }^{9}$ The parameter of interest is $\phi$, the average effect of receiving the e-mail on the outcome of interest.

Our main interest in this article, however, is the effect of smartvote use on partisan vote intentions. Because not every e-mail recipient uses smartvote and not every smartvote user received the e-mail, $\phi$ identifies an intention-to-treat (ITT) effect of receiving the e-mail. The overall effect of the e-mail treatment estimated by equation (1) is a combination of the rate at which e-mail recipients use smartvote and of the effect of smartvote use on the outcomes of interest. Given imperfect compliance with the e-mail treatment, the estimated ITT effect by equation (1) will differ from the effect of smartvote use on the outcomes of interest. However, the random assignment of the e-mail treatment generates plausible exogenous variation in smartvote use, which we leverage to identify the causal effect of smartvote use on vote intentions.

We use the following model to link changes in vote intentions to smartvote use and explanatory control variables:

$$
y_{i}=\beta \text { smartvote }_{i}+\alpha^{\prime} X_{i}+\eta_{i},
$$

where smartvote $\mathrm{i}_{\mathrm{i}}$ is an indicator of smartvote use and $X_{i}$ is a vector of measured background characteristics. The parameter of interest, $\beta$, measures the association between smartvote use and changes in vote intentions.

Note that selection into smartvote use based on unobserved and unignorable characteristics may bias estimates of equation (2). For instance, it is likely that individuals receive other

9. While in principle, the experimental setup should not require including additional covariates, potential nonrandom attrition led us to introduce covariates. Note, however, that qualitative results are unchanged when estimating the models without covariates. new information that also may affect their vote intentions. To the extent that these confounding effects are not entirely captured by the other control variables, $X_{i}$, they will enter the error term, $\eta_{i}$, in equation (2). The validity of any estimator of $\beta$ that relies on a selection-on-observables assumption (such as an ordinary least squares [OLS] estimation) hinges on whether these confounding effects that enter the error term, $\eta_{i}$, are also correlated with the probability to use smartvote. In other words, smartvote use is endogenous and OLS estimates of $\beta$ are biased if unobserved factors that affect political preferences also affect the probability to use smartvote.

The exogenous variation in smartvote use produced by the random assignment of the e-mail treatment in our experiment can be exploited to solve the endogeneity of smartvote use. As e-mail receipt is assigned randomly, we can estimate a two-stage least-squares (2SLS) model with e-mail receipt as the instrument. In the just-identified model in which e-mail ${ }_{i}$ is the only instrument for the endogenous variable smartvote $e_{i}$, the first-stage model relating e-mail receipt to smartvote use is

$$
\text { smartvote }_{i}=\gamma \mathrm{e}-\text { mail }_{i}+\pi^{\prime} X_{i}+\mu_{\mathrm{i}}
$$

where $\gamma$ is the first-stage effect of the instrument. The parameter corresponds to the compliance rate with the e-mail treatment. ${ }^{10}$ The resulting instrumental variable (IV) estimation now substitutes the actual smartvote use in equation (2) with the predicted values of smartvote $e_{i}$ from equation (3) to obtain an estimate of $\beta$. The intuition of the IV estimation is that it uses only the variation in smartvote use induced by

10. We model the first stage as linear, despite the binary nature of the outcome variable. According to Angrist and Krueger (2001, 80), "using a linear regression for the first-stage estimates generates consistent secondstage estimates even with a dummy endogenous variable." Estimations using bivariate probit models produce qualitatively similar results (available from the authors). 
Table 2. Change in Availability for Electoral Competition before and after Treatment

\begin{tabular}{lcc}
\hline Scenario & Pretreatment & Posttreatment \\
\hline 1 & 0 & 0 \\
2 & 1 & 1 \\
3 & 0 & 1 \\
4 & 1 & 0 \\
\hline
\end{tabular}

the e-mail receipt to estimate the effect of smartvote use on partisan vote intentions. Note that the IV estimate of the effect of e-mail-induced smartvote use on vote intentions corresponds to the ITT effect of the e-mail treatment, $\phi$, divided by the compliance rate estimated by the first-stage coefficient, $\gamma$.

The key advantage of the IV estimation is that it produces estimates of the effect of smartvote use that have a direct causal interpretation under plausible identifying assumptions. In particular, as e-mail treatment is assigned randomly, IV estimates identify a causal effect of smartvote use under the assumption that receiving the e-mail has no impact on partisan vote intentions other than through the effect it has on smartvote use.

While the IV estimation of the effect of smartvote use on partisan vote intentions helps to overcome concerns about unobserved confounding factors that may bias simple OLS estimates in equation (2), it is important to note that the IV estimate of $\beta$ identifies the average effect of smartvote use on vote intentions for compliers only. That is, it identifies the local average treatment effect (LATE) for individuals who use smartvote when receiving the e-mail but would not have used smartvote if they had not received the e-mail (Imbens and Angrist 1994). Thus, even in the absence of confounding impacts of unobserved factors, the IV estimate may differ from an OLS estimate if the average effect of smartvote use for compliers is different from the average effect of smartvote use for students who would have used smartvote anyway.

Our approach relies on two important assumptions (Angrist, Imbens, and Rubin 1996). First, the exclusion restriction assumes that the encouragement itself has no effect on the outcome other than through its effect on the acceptance of treatment (Angrist et al. 1996). In other words, the invitation e-mail to use smartvote should be predictive of actual smartvote use, but the e-mail itself should have no direct effect on the vote intentions of participants. We made sure that all study participants' attention was drawn to the upcoming election in the first survey wave and that the email invitation only added information on the existence of smartvote. Hence, attentiveness to the elections and subsequent information searches should have been evoked, if at all, for all study participants before treatment assignment.
Thus, we do expect that the encouragement should not have induced any other behavior among participants than to actually use smartvote.

Second, the stable unit treatment value assumption in the counterfactual framework implies no interference among units (Rosenbaum 2007, 191). The assumption implies that the encouragement status of one participant has no effect on the encouragement status, the treatment status, or the outcome of interest of any other study participant. Given that our experiment took place among university students, chances are that participants exchanged information with regard to the randomized treatment assignment. As such, it is possible that students of the treatment group informed students of the control group about the treatment, possibly leading students in the control group to use the tool although we did not encourage them to do so. Interference among units is problematic since it cannot only affect the compliance rate but further complicates the identification of treatment effects. If we assume that smartvote use does initiate change in vote intentions, then interference among units in our case most likely leads us to underestimate the reported effectseither through a reduced compliance rate or through affected potential outcomes among the control units.

\section{THE IMPACT OF THE RANDOMIZED E-MAIL TREATMENT}

We start by estimating equation (3), with the results shown in table 3, which reveals the compliance rate with the e-mail treatment. ${ }^{11}$ Each row of table 3 provides the results for an estimated model for the dependent variable specified. Column 1 of table 3 provides the mean baseline values of each covariate, column 2 provides estimates without controls, and column 3 gives estimates including controls. ${ }^{12}$ Beginning with the first row of table 3 , the estimated coefficient on the dummy variable indicating e-mail receipt identifies the causal effect of the randomized e-mail treatment on smartvote use. The coefficient of 0.14 corresponds to the compliance rate with the e-mail treatment. Note that controlling for observable characteristics does not change the estimate, which is expected given that e-mail receipt is randomly assigned. The estimates

11. We use linear models, despite the binary nature of some of the outcome variables. We regard the OLS results as a linear approximation of the conditional expectation function of interest, as suggested in Angrist and Pischke (2009). Probit estimations produce identical results for the effects of interest (results available from the authors on request).

12. We do not report standard deviations in col. 1 of table 3 , as most of these variables are binary indicators. The variable that is not binary is the Difference in top PTV score, and the standard deviation for that mean is 1.13 . 
Table 3. The Impact of the Randomized E-Mail Treatment

\begin{tabular}{|c|c|c|c|}
\hline \multirow[b]{2}{*}{ Dependent Variable } & \multirow[b]{2}{*}{$\begin{array}{c}\text { Baseline Mean } \\
\text { (1) }\end{array}$} & \multicolumn{2}{|c|}{ Effect of E-Mail Treatment } \\
\hline & & $\begin{array}{c}\text { No Controls } \\
\text { (2) }\end{array}$ & $\begin{array}{c}\text { With Controls } \\
\text { (3) }\end{array}$ \\
\hline Smartvote used & .69 & $\begin{array}{l}.14^{* * *} \\
(.02)\end{array}$ & $\begin{array}{l}.14^{* * *} \\
(.02)\end{array}$ \\
\hline Difference in top PTV score & .14 & $\begin{array}{l}.10^{* *} \\
(.05)\end{array}$ & $\begin{array}{l}.10^{* *} \\
(.05)\end{array}$ \\
\hline Same top PTV party & .95 & $\begin{array}{c}-.01 \\
(.01)\end{array}$ & $\begin{array}{c}-.01 \\
(.01)\end{array}$ \\
\hline Change in multiple intentions & .20 & $\begin{array}{l}.04^{*} \\
(.02)\end{array}$ & $\begin{array}{l}.03 \\
(.02)\end{array}$ \\
\hline Newly available to electoral competition & .11 & $\begin{array}{r}.03^{*} \\
(.02)\end{array}$ & $\begin{array}{r}.03^{*} \\
(.02)\end{array}$ \\
\hline
\end{tabular}

Note. Baseline values reported in col. 1 are the means of the respective outcome for the control group. Columns 2 and 3 provide model estimates, without control variables (col. 2) and with control variables (col. 3). Control variables include age, gender, highest level of education obtained, university location, field of study, and political interest. Detailed descriptive statistics on all control variables are reported in table 1 . Survey data were specifically collected in connection with the smartvote experiment conducted in 2011. Standard errors in parentheses. PTV = propensity to vote; $N=1,775$.

${ }^{*} p<.10$.

${ }^{* *} p<.05$.

${ }^{* * *} p<.01$

show that receiving the e-mail increases the probability of smartvote use by 14 percentage points. This effect is highly significant, indicating that receiving the e-mail treatment had a significant impact on smartvote use.

The other rows of table 3 report estimated ITT effects. That is, we estimate equation (1), which reveals the reduced form effect of the e-mail treatment on the outcomes of interest. As the e-mail treatment is randomly assigned, the estimated coefficients have a direct causal interpretation. We start in the second row of table 3 with the outcome of interest being the difference in PTV scores for the most preferred party-before and after the elections. We label this variable Difference in top PTV score. The estimated coefficients show that e-mail receipt significantly increases the intention to vote for the most preferred party by 0.1 PTV scores. Additionally, controlling for observable characteristics does not affect the estimate. The magnitude of the reduced-form effect is quite sizable compared to the baseline difference in PTV scores for the most preferred party among individuals in the control group. The baseline difference is 0.14 PTV scores, as can be seen in column 1 of table 3 . This implies that e-mail receipt increased the intention to vote for the most preferred party by about $66 \%$ of the baseline difference. We generally assessed average changes in PTV scores per party rank between the control and treatment group and found that in both the treatment and control groups, average PTV scores increased posttreatment. In other words, participants tended to generally rate parties more favorably in the second survey wave. Significant differences with regard to PTV scores were, however, only present for the highest ranked party vote intention (see fig. A.2).

As discussed in the section on measuring change in vote intention, the effect on the top PTV score may reflect an increase in the intent to vote for the most preferred party as reported in the first wave of the survey, or it may reflect that students now intend to vote for a different party and report an even higher PTV score for this new party. The constructed dummy variable Same top PTV party shows that e-mail receipt had no impact on a change in the party receiving the highest PTV score before and after the election. Moreover, note that the baseline value is .95 as reported in column 1 of table 3 . This indicates that in $95 \%$ of all cases students assigned the highest PTV score after the election to the same party that received the highest PTV score before the election.

The last two rows of table 3 show a significant effect of email receipt on both the Change in multiple vote intentions and the Newly available to electoral competition measures that we defined in the section on measuring change in vote intention. These effects are significant at the $10 \%$ confidence level except for the estimate of the effect on the Change in multiple intentions with additional control variables, where the $p$-value is exactly .1. These results indicate that e-mail 
Table 4. The Effect of smartvote Use on Partisan Vote Intentions

OLS

(1)

Difference in top PTV score

Same top PTV party

Change in multiple intentions

Newly available to electoral competition

Controls

IV

(3)

$\begin{array}{cc}.76^{* *} & .74^{* *} \\ (.38) & (.37) \\ -.08 & -.07 \\ (.08) & (.08) \\ .26^{*} & .24 \\ (.15) & (.15) \\ .20^{*} & .20^{*} \\ (.12) & (.12) \\ & \checkmark\end{array}$

Note. Control variables include age, gender, highest level of education obtained, university location, field of study, and political interest. Detailed descriptive statistics on all control variables are reported in table 1. Survey data were specifically collected in connection with the smartvote experiment conducted in 2011. Standard errors in parentheses. OLS $=$ ordinary least squares; IV $=$ instrumental variable; PTV $=$ propensity to vote; $N=1,775$.

${ }^{*} p<.10$.

${ }^{* *} p<.05$.

${ }_{* * *}^{*} p<.01$.

receipt led voters, who initially did not have multiple high party vote intentions, to newly evaluate at least one other party as a viable vote option.

\section{The impact of using smartvote on partisan vote intentions}

Table 4 shows OLS and IV estimates of smartvote use on the same set of outcomes, with and without controls. ${ }^{13}$ In the first row, we see estimates of the effect of smartvote use on the difference in PTV scores for the highest rated party. The OLS estimates suggest a relatively small positive effect of smartvote use that is significant at the $10 \%$ level only when other control variables are included in the model. In contrast, the IV results indicate a substantial and highly significant effect of smartvote use on PTV scores for the highest rated party. The IV point estimates suggest that using smartvote increases the intention to vote for the most preferred party by about 0.7 PTV scores, which is roughly seven times as large as the OLS estimate. ${ }^{14}$

13. The estimated first-stage effects of the IV approach are reported in row 1 of table 3 . The results confirm that the e-mail treatment is a relevant instrument for smartvote use. Stock, Wright, and Yogo (2002) argue that the $F$-statistic on excluded instruments must be large, typically exceeding 10, for 2SLS inference to be reliable. The F-statistics on our excluded instrument are 46.76 in the model without further covariates (col. 2 of table 3 ) and 48.57 in the model with further covariates (col. 3 of table 3). These F-statistics clearly exceed the threshold value of 10 . We thus conclude that e-mail treatment is a valid instrument.

14. The more conservative estimation of predicting posttreatment PTV scores as a function of smartvote use and pretreatment PTV scores yields identical results (coefficient $0.68, p<.05$ ).
As discussed earlier, the difference between IV and OLS estimates may arise because OLS estimates may be biased downward or because IV identifies a LATE for compliers while OLS identifies an average treatment effect for all treated. While it is impossible to determine what exactly causes this difference, the IV estimates have a direct causal interpretation under a very plausible identifying assumption. We regard our IV results as the best available evidence that smartvote use increases the intention to vote for the most preferred party.

The second row of table 4 shows that smartvote use has no impact on the choice of the highest rated party. ${ }^{15}$ Neither OLS nor IV estimates are significantly different from zero. This clearly implies that the increase in propensity scores for the highest rated party does not conceal a change in the highest rated party but rather reflects that smartvote use strengthens the confidence of voters in their ex ante highest rated party.

While smartvote use reinforces confidence in the highest rated party, it may also cause voters to revise their assessment of parties other than their highest rated one. Rows 4 and 5 show estimation results for our two measures of change

15. Nonlinear second-stage estimates with continuous or multivalued regressors require a correctly specified functional form in order to interpret the estimates easily. We use a 2SLS procedure, although the following three dependent variables are binary. According to Angrist and Krueger $(2001,80)$, "even if the underlying second-stage relationship is nonlinear, 2SLS typically captures an average effect of economic interest analogous to the LATE parameter for dummy endogenous regressors." 
in terms of multiple high party ratings. While the OLS results indicate no effect of smartvote use on these outcome measures, IV estimates show that among compliers with the randomized e-mail treatment smartvote use has a positive effect on these outcomes. In particular, smartvote use increased the probability that voters, who initially did not have multiple party vote intentions, evaluate at least one other party as a viable vote option by about $20 \%$.

\section{Who uses smartvote because of the encouragement? Characterizing compliers}

In the LATE framework, the individuals who use smartvote because of the e-mail treatment are the compliers. Naturally, some use smartvote regardless of whether they receive the e-mail. Because it is impossible to know whether a student who received the e-mail would have used smartvote had he or she not received the e-mail, compliers cannot be individually identified. However, it is possible to describe the distribution of characteristics of the compliers by making use of the variation in the first-stage estimates across covariate groups, as shown in Angrist and Pischke (2009, 168). This characterization is important for two reasons: First, as discussed in the empirical section, our preferred IV estimates identify a causal effect of smartvote use only for the complier population. Thus, it is interesting to see whether this population differs systematically in terms of some observable characteristics from the average smartvote user in the sample. Second, the characterization of the complier population is of direct interest from a policy perspective. Provided that stimulating smartvote use is a desirable policy goal, any campaign that informs an electorate about the existence of smartvote will presumably affect the behavior of a complier population that is similar to the complier population in our smartvote experiment.

Average characteristics for compliers are reported in table 5. Column 3 shows the relative likelihood for compliers given the characteristic indicated in each row. We excluded characteristics possessed by less than $5 \%$ of all students in the sample. We see that women are more likely to comply with the e-mail treatment than are men, students holding a high school degree are more likely to comply than students holding some advanced degree already, and politically less interested participants are somewhat more likely to comply.

\section{CONCLUSION}

The main goal of this article was to determine whether partisan vote intentions change as a consequence of using a VAA before casting a vote. This was hypothesized since the tailor-made voting recommendation allows users to systematically evaluate and compare the electoral offer relative to their own position in the political landscape, an information gain that might revise previously held beliefs. To empirically assess whether VAA information affects electoral vote intentions, we used an online

Table 5. Characterizing Compliers

\begin{tabular}{|c|c|c|c|}
\hline Variable & $\begin{array}{l}\text { Average Sample } \\
\text { (1) }\end{array}$ & $\begin{array}{l}\text { Average Compliers } \\
\text { (2) }\end{array}$ & $\begin{array}{l}\text { Relative Likelihood } \\
\text { (3) }\end{array}$ \\
\hline \multicolumn{4}{|c|}{ Demographic characteristic: } \\
\hline Female & .50 & .61 & 1.22 \\
\hline Age above 23 & .52 & .51 & .99 \\
\hline \multicolumn{4}{|l|}{ Level of education: } \\
\hline High school & .53 & .70 & 1.31 \\
\hline Bachelor (academic) & .26 & .15 & .56 \\
\hline Master (academic) & .16 & .09 & .58 \\
\hline \multicolumn{4}{|l|}{ Field of study: } \\
\hline Social science & .48 & .48 & 1.01 \\
\hline Medicine & .09 & .08 & .92 \\
\hline Natural science & .15 & .14 & .95 \\
\hline Law & .17 & .17 & 1.00 \\
\hline Economics & .10 & .08 & .84 \\
\hline \multicolumn{4}{|l|}{ Interest in politics: } \\
\hline Rather not interested & .06 & .09 & 1.41 \\
\hline Rather interested & .44 & .43 & .97 \\
\hline Very interested & .49 & .48 & .99 \\
\hline
\end{tabular}

Note. Analysis of complier characteristics. The ratio in col. 3 shows the relative likelihood that the compliers have the characteristics indicated in each row. Survey data were specifically collected in connection with the smartvote experiment conducted in 2011. 
field experiment during the 2011 Swiss federal elections. We employed an encouragement design and invited a random sample of respondents to use the Swiss VAA smartvote before the elections. Since the control group did not receive such an invitation, we were able to relate changes in electoral vote intentions to smartvote use.

Smartvote has become a popular tool in the election campaigns in Switzerland over the last several years; thus, we were faced with noncompliance in our research design. Whereas $83 \%$ of our treatment group took up our invitation and used smartvote before the elections, $69 \%$ of the control group did so as well without our asking them to. Given the large share of smartvote users within the control group, we applied an IV approach in which random treatment assignment served as an exogenous source for inducing smartvote use. In our analysis of group differences, we thus identify and report the LATE of smartvote use on partisan vote intentions.

Our results revealed that participants who were exposed to the VAA and used it before casting their vote were significantly more likely to strengthen their vote intentions for their most preferred party. We believe that this outcome arises through the mechanism of motivated reasoning, with participants who used smartvote indicating less uncertainty with regard to their highest rated party compared to those respondents who did not use the VAA. We also examined whether smartvote users were more likely to change their highest vote intention to another party, but we could not find a significant difference-most voters, irrespective of smartvote use, stayed with their initial party vote intention. Our findings furthermore indicate that those participants who used smartvote were significantly more likely to change their vote intentions so as to consider more than one party as an eligible vote option. The multiplication of highly rated parties among smartvote users implies an increase in their availability for electoral competition, making them become ambivalent partisans; a change in vote intention that can have behavioral implications in an electoral system where crossparty voting is possible. As such, parties that rival the highest rated party might not only gain votes on the ballot but have the potential to replace the top-rated party in future vote decisions.

Finding the aforementioned changes in the partisan vote intentions of VAA users is interesting since the experimental sample likely consists of students who are generally more interested in politics than students who did not participate in the study. As such, we expect that changes in vote intention would be less likely to occur among predisposed voters since their priors are probably already well informed. The results suggest that smartvote can provide information to voters that might not have been considered before, even among a politically attentive group of voters, causing them to adapt their partisan vote intentions accordingly.

While in other contexts survey-based experiments have been shown to produce results that are generalizable to a wider population (Barabas and Jerit 2010), like with all experimental studies, some may question our study's external validity (Druckman and Kam 2011). First, we exclusively deal with the Swiss case. Like Hainmueller and Hangartner (2013, 185), as well as Bechtel, Hangartner, and Schmid (2015), we refrain from either over- or undergeneralizing beyond Switzerland to a cross-national context. Still, Switzerland is an important case for testing our hypotheses, presenting a very open electoral system with an impressively high number of political parties and one of the largest proportions of VAA users in any given electorate. Second, our experiment focuses on university students. Thus, our findings are not representative of the Swiss electorate but rather for a specific group of voters: young, highly educated voters with an interest in politics. However, note that this should underestimate the more general effect of VAA exposure on vote intentions. Although university students are often a convenience sample, in our case they represent the most frequent VAA users (Alvarez et al. 2014; Ladner, Fivaz, and Pianzola 2012; Vassil 2012). Finding change in vote intentions among a highly educated and politically interested group of citizens is important since we would expect their political predispositions to already be well informed and thus less amenable to change (Zaller 1992). However, as we argue, their ability to learn from the tailormade information provided to them by the VAA affects their vote intentions accordingly. Our theoretical expectations, derived from Bayesian learning theory, could be matched by our empirical analyses. At the same time, young voters are seen as generally more susceptible to persuasion and less consistent in their vote intentions, making them potentially more receptive toward external influences (Kroh, van der Brug, and van der Eijk 2007; van der Eijk and Franklin 2009, 101; Visser and Krosnick 1998). A closer view of the characteristics of compliers suggests that politically less interested participants in the sample were somewhat more likely to comply with the encouragement. As such, the observed changes in vote intentions might be driven by the politically less interested and thus less informed participants, yet the subgroup of compliers remains a hypothetical entity within the sample, and we will never know exactly which participants belong to it (Bullock and Ha 2011, 515). Hence, politically interested and informed participants might have also been affected by the VAA. Furthermore, whether the remaining cohorts of the electorate are less prone to the influence of a VAA on their vote intentions has yet to be empirically assessed. 
In conclusion, the results reported here provide evidence that the VAA smartvote reveals new information that leads a specific group of users to change their vote intentions accordingly. By using a randomized field experiment, and through our statistical analysis of our experimental results, we have identified and estimated the causal effects of VAA use on voter's vote intentions in the course of an electoral campaign. Isolating these causal effects of VAA use has not been possible in past studies, as they have been observational in nature and thus have lacked the methodological rigor of our study. Clearly, as VAA use is proliferating rapidly across the world, a more extensive scientific understanding of the effects of its use on voter opinions and behaviors is a critical question for students of electoral politics.

\section{ACKNOWLEDGMENTS}

We would like to thank the following institutions that supported this research by giving us the time to work on the project, access to data, and financial support for participating in conferences and meetings: Swiss Graduate School of Public Administration (University of Lausanne), the Politools team, NCCR Democracy (University of Zurich), Swiss Chair on Federalism and Democracy at the Department of Political and Social Sciences of the European University Institute (EUI) in Florence (financed by the Swiss State Secretariat for Education, Research and Innovation), European Union Democracy Observatory at the Robert Schuman Center for Advanced Studies at the EUI, smartvote, University of Zurich, ETH Zurich, University of Bern, and University of Lucerne. We also thank the participants of the panel on Technology, Elections and Politics in the Western Political Science Association Annual Meeting 2013 in Hollywood, $\mathrm{CA}$, as well as the seminar participants at the Ifo Institute in Munich and the University of Konstanz. Finally, we would like to thank Andreas Ladner and Diego Garzia for their comments on earlier versions.

\section{REFERENCES}

Achen, Christopher H. 1992. "Social Psychology, Demographic Variables, and Linear Regression: Breaking the Iron Triangle in Voting Research." Political Behavior 14 (3): 195-211.

Althaus, Scott L. 2003. Collective Preferences in Democratic Politics: Opinion Surveys and the Will of the People. New York: Cambridge University Press.

Alvarez, R. Michael. 1998. Information and Elections. Rev. ed. Ann Arbor: University of Michigan Press.

Alvarez, R. Michael, and John Brehm. 2002. Hard Choices, Easy Answers: Values, Information, and American Public Opinion. Princeton, NJ: Princeton University Press.

Alvarez, R. Michael, and Charles H. Franklin. 1994. "Uncertainty and Political Perceptions.” Journal of Politics 56 (3): 671-88.
Alvarez, R. Michael, Inés Levin, Alexander H. Trechsel, and Kristjan Vassil. 2014. "Voting Advice Applications: How Useful and for Whom?" Journal of Information Technology and Politics 11 (1): 82-101.

Angrist, Joshua D., Guido W. Imbens, and Donald B. Rubin. 1996. "Identification of Causal Effects Using Instrumental Variables." Journal of the American Statistical Association 91 (434): 444-55.

Angrist, Joshua D., and Alan B. Krueger. 2001. "Instrumental Variables and the Search for Identification: From Supply and Demand to Natural Experiments." Journal of Economic Perspectives 15 (4): 69-85.

Angrist, Joshua D., and Jörn-Steffen Pischke. 2009. Mostly Harmless Econometrics: An Empiricist's Companion. Princeton, NJ: Princeton University Press.

Barabas, Jason, and Jennifer Jerit. 2010. "Are Survey Experiments Externally Valid?” American Political Science Review 104 (2): 226-42.

Barker, David C., and Susan B. Hansen. 2005. "All Things Considered: Systematic Cognitive Processing and Electoral Decision-Making." Journal of Politics 67 (2): 319-44.

Bartels, Larry M. 1986. "Issue Voting under Uncertainty: An Empirical Test.” American Journal of Political Science 30 (4): 709-28.

Bartels, Larry M. 1993. "Messages Received: The Political Impact of Media Exposure.” American Political Science Review 87 (2): 267-85.

Bartels, Larry M. 1996. "Uninformed Votes: Information Effects in Presidential Elections.” American Journal of Political Science 40 (1): 194230.

Bartels, Larry M. 2002. "Beyond the Running Tally: Partisan Bias in Political Perceptions.” Political Behavior 24 (2): 117-50.

Bartolini, Stefan. 2002. "Electoral and Party Competition: Analytical Dimensions and Empirical Problems." In Richard Gunther, Juan J. Linz, and José R. Montero, eds., Political Parties: Old Concepts and New Challenges. Oxford: Oxford University Press, 84-110.

Bartolini, Stefan, and Peter Mair. 1990. Identity, Competition, and Electoral Availability: The Stabilisation of European Electorates, 1885-1985. Cambridge: Cambridge University Press.

Bechtel, Michael M., Dominik Hangartner, and Lukas Schmid. 2015. "Does Compulsory Voting Increase Support for Leftist Policy?” American Journal of Political Science 60 (3): 752-67.

Bullock, John G., and Shang E. Ha. 2011. "Mediation Analysis Is Harder than It Looks.” In James N. Druckman, Donald Green, James H. Kuklinski, and Arthur Lupia, eds., Cambridge Handbook of Experimental Political Science. Cambridge: Cambridge University Press, 508-21.

Campbell, Angus, Philip E. Converse, Warren E. Miller, and Donald E. Stokes. 1960. The American Voter: Unabridged Edition. Chicago: University of Chicago Press.

Cedroni, Lorella, and Diego Garzia, eds. 2010. Voting Advice Applications in Europe: The State of the Art. Naples: Scriptaweb.

Converse, Philip E. 1964. "The Nature of Belief Systems in Mass Publics." In David E. Apter, ed., Ideology and Discontent. London: Free Press of Glencoe, 206-61.

Dinas, Elias. 2014. "Does Choice Bring Loyalty? Electoral Participation and the Development of Party Identification." American Journal of Political Science 58 (2): 449-65.

Dinas, Elias, Alexander H. Trechsel, and Kristjan Vassil. 2014. "A Look in the Mirror: Preferences, Representation, and Electoral Participation.” Electoral Studies 36 (December): 290-97.

Downs, Anthony. 1957. An Economic Theory of Democracy. New York: Harper \& Brothers.

Druckman, James N., and Cindy D. Kam. 2011. "Students as Experimental Participants: A Defense of the 'Narrow Data Base.'” In James N. Druckman, Donald Green, James H. Kuklinski, and Arthur Lupia, eds., Cambridge Handbook of Experimental Political Science. Cambridge: Cambridge University Press, 41-57. 
Enyedi, Zsolt. 2015. "The Influence of Voting Advice Applications on Preferences, Loyalties and Turnout: An Experimental Study." Political Studies 64 (4): 1000-1015.

Festinger, Leon. 1957. A Theory of Cognitive Dissonance. Evanston, IL: Row, Peterson.

Fiorina, Morris P. 1977. "An Outline for a Model of Party Choice." American Journal of Political Science 21 (3): 601-25.

Fiorina, Morris P. 1981. Retrospective Voting in American National Elections. New Haven, CT: Yale University Press.

Fournier, Patrick. 2009. "The Impact of Campaigns on Discrepancies, Errors, and Biases in Voting Behavior." In Henry E. Brady and Richard Johnston, eds., Capturing Campaign Effects. Ann Arbor: University of Michigan Press, 45-77.

Franklin, Charles H. 1991. "Eschewing Obfuscation? Campaigns and the Perceptions of Senate Incumbents." American Political Science Review 85 (4): 1193-214.

Gaines, Brian J., James H. Kuklinski, Paul J. Quirk, Buddy Peyton, and Jay Verkuilen. 2007. "Same Facts, Different Interpretations: Partisan Motivation and Opinion on Iraq." Journal of Politics 69 (4): 957-74.

Garzia, Diego, and Stefan Marschall. 2012. "Voting Advice Applications under Review: The State of Research." International Journal of Electronic Governance 5 (3/4): 203-22.

Garzia, Diego, and Stefan Marschall, eds. 2014. Matching Voters with Parties and Candidates: Voting Advice Applications in Comparative Perspective. Colchester: ECPR.

Gemenis, Kostas, and Martin Rosema. 2014. "Voting Advice Applications and Electoral Turnout." Electoral Studies 36 (December) 281-89.

Hainmueller, Jens, and Dominik Hangartner. 2013. "Who Gets a Swiss Passport? A Natural Experiment in Immigrant Discrimination." American Political Science Review 107 (1): 159-87.

Imbens, Guido W., and Joshua D. Angrist. 1994. "Identification and Estimation of Local Average Treatment Effects." Econometrica 62 (2): 467-75.

Kriesi, Hanspeter, and Alexander H. Trechsel. 2008. The Politics of Switzerland: Continuity and Change in a Consensus Democracy. Cambridge: Cambridge University Press.

Kroh, Martin, Wouter van der Brug, and Cees van der Eijk. 2007. "Prospects for Electoral Change." In Wouter der van Brug and Cees der van Eijk, eds., European Elections and Domestic Politics: Lessons from the Past and Scenarios for the Future. Notre Dame, IN: University of Notre Dame Press, 209-25.

Kuklinski, James H., and Buddy Peyton. 2007. "Belief Systems and Political Decision Making." In Russell J. Dalton and Hans-Dieter Klingemann, eds., Oxford Handbook of Political Behavior. Oxford: Oxford University Press, 45-64.

Kunda, Ziva. 1990. “The Case for Motivated Reasoning." Psychological Bulletin 108 (3): 480-98.

Ladner, Andreas. 2004. Stabilität und Wandel von Parteien und Parteiensystemen: Eine vergleichende Analyse von Konfliktlinien, Parteien und Parteiensystemen in den Schweizer Kantonen. Wiesbaden: Sozialwissenschaften.

Ladner, Andreas, Jan Fivaz, and Joëlle Pianzola. 2012. "Use of Voting Advice Applications and Party Choice: Evidence from smartvote Users in Switzerland." International Journal of Electronic Governance 5 (3/4): $367-87$.

Ladner, Andreas, and Joëlle Pianzola. 2010. "Do Voting Advice Applications Have an Effect on Electoral Participation and Voter Turnout? Evidence from the 2007 Swiss Federal Elections." Presented at the second IFIP WG 8.5 International Conference, Lausanne.

Lau, Richard R., and David P. Redlawsk. 1997. "Voting Correctly." American Political Science Review 91 (3): 585-98.
Lau, Richard R., and David P. Redlawsk. 2006. How Voters Decide: Information Processing during Election Campaigns. Cambridge: Cambridge University Press.

Lavine, Howard G., Christopher D. Johnston, and Marco R. Steenbergen. 2012. The Ambivalent Partisan: How Critical Loyalty Promotes Democracy. New York: Oxford University Press.

Lefevere, Jonas, and Stefaan Walgrave. 2014. "A Perfect Match? The Impact of Statement Selection on Voting Advice Application's Ability to Match Voters and Parties." Electoral Studies 36 (December): 25262 .

Lenz, Gabriel. 2009. "Learning and Opinion Change, Not Priming: Reconsidering the Priming Hypothesis." American Journal of Political Science 53 (4): 821-37.

Lodge, Milton, and Charles Taber. 2000. "Three Steps toward a Theory of Motivated Political Reasoning." In Arthur Lupia, Matthew McCubbins, and Samuel L. Popkin, eds., Elements of Reason: Cognition, Choice and Bounds of Rationality. Cambridge: Cambridge University Press, 183213.

Lodge, Milton, and Charles Taber. 2013. The Rationalizing Voter. New York: Cambridge University Press.

Luskin, Robert C. 2002. "From Denial to Extenuation (and Finally Beyond): Political Sophistication and Citizen Performance." In James H. Kuklinski, ed., Thinking about Political Psychology. New York: Cambridge University Press, 281-305.

Lutz, Georg. 2010. "First Come, First Served: The Effect of Ballot Position on Electoral Success in Open Ballot PR Elections." Representation 46 (2): 167-81.

MacKuen, Michael, Robert S. Erikson, James A. Stimson, and Kathleen Knight. 2003. "Elections and the Dynamics of Ideological Representation." In Michael MacKuen and George Rabinowitz, eds., Electoral Democracy. Ann Arbor: University of Michigan Press, 200-237.

Maheo, Valerie-Anne. 2016. "The Impact of Voting Advice Applications on Electoral Preferences: A Field Experiment in the 2014 Quebec Election." Policy and Internet 8 (4): 391-411.

Mair, Peter. 1987. The Changing Irish Party System: Organisation, Ideology and Electoral Competition. London: Pinter.

Otjes, Simon, and Tom Louwerse. 2014. "Spatial Models in Voting Advice Applications." Electoral Studies 36 (December): 263-71.

Pajala, Tommi, Pekka Korhonen, Pekka Malo, Ankur Sinha, Jyrki Wallenius, and Akram Dehnokhalaji. 2017. "Accounting for Political Opinions, Power, and Influence: A Voting Advice Application." European Journal of Operational Research 266 (2): 702-15.

Pianzola, Joëlle. 2014a. "Mirror Me: The Effect of the Voting Advice Application Smartvote on Voting Preferences and Behavior of Swiss Voters." PhD diss., University of Lausanne.

Pianzola, Joëlle. 2014b. "Selection Biases in Voting Advice Application Research.” Electoral Studies 36 (3): 272-80.

Rosenbaum, Paul R. 2007. "Interference between Units in Randomized Experiments." Journal of the American Statistical Association 102 (477): 191-200.

Stock, James H., Jonathan H. Wright, and Motohiro Yogo. 2002. "A Survey of Weak Instruments and Weak Identification in Generalized Method of Moments." Journal of Business and Economic Statistics 20 (4): 518-29.

Taber, Charles, and Milton Lodge. 2006. "Motivated Skepticism in the Evaluation of Political Beliefs." American Journal of Political Science 50 (3): 755-69.

Trechsel, Alexander H., and Peter Mair. 2011. "When Parties (Also) Position Themselves: An Introduction to the EU Profiler." Journal of Information Technology and Politics 8 (1): 1-20.

Van der Eijk, Cees, and Mark N. Franklin. 2009. Elections and Voters. Basingstoke, NY: Palgrave Macmillan. 
Van der Eijk, Cees, and Broer Niemoeller. 1984. "Het Potentiele Electoraat van de Nederlandse Politieke Partijen." Beleid en Maatschappij 11:192204.

Van der Eijk, Cees, and Erik V. Oppenhuis. 1991. "European Parties" Performance in Electoral Competition.” European Journal of Political Research 19 (1): 55-80.

Van der Eijk, Cees, Wouter Van der Brug, Martin Kroh, and Mark Franklin. 2006. "Rethinking the Dependent Variable in Voting Behavior: On the Measurement and Analysis of Electoral Utilities.” Electoral Studies 25 (3): 424-47.

Vassil, Kristjan. 2012. "Voting Smarter? The Impact of Voting Advice Applications on Political Behavior." PhD diss., European University Institute.
Visser, Penny S., and Jon A. Krosnick. 1998. "Development of Attitude Strength over the Life Cycle: Survey and Decline." Journal of Personality and Social Psychology 75 (6): 1389-410.

Walgrave, Stefaan, Jonas Lefevere, Koen Pepermans, and Michiel Nuytemans. 2009. "Why Representation Fails: Determinants of Incorrect Voting in a Crowded Party System." Paper presented at the National Center of Competence in Research Democracy Workshop on Political Representation: New Ways of Measuring and Old Challenges.

Wheatley, Jonathan. 2016. "Cleavage Structures and Dimensions of Ideology in English Politics: Evidence from Voting Advice Application Data." Policy and Internet 8 (4): 457-77.

Zaller, John R. 1992. The Nature and Origins of Mass Opinion. Cambridge: Cambridge University Press. 